\title{
Comparative Study of Oil Production Forecast by Decline Curve Analysis and Material Balance
}

\author{
Anyadiegwu Charley Iyke and Ohia Nnaemeka Princewill
}

\begin{abstract}
Comparative analysis of forecast of rate of production of oil from a reservoir using decline curve analysis and material balance was presented. The data for reservoir A Located Southeast, Nigeria was obtained for the study. The analysis on the well using decline curve analysis showed that the rate of production from the well over the years followed an exponential method of decline. The rate of production of the well was predicted to be $158 \mathrm{stb} /$ day in 2020 . The second analysis on the well was performed using material balance with MBAL. The rate of production of the well was predicted to be 411.984 stb/day in 2020. It was also read from MBAL that the well will have a constant flow rate from the $20^{\text {th }}$ year to the $31^{\text {st }}$ year of the producing life of the well which is 2020 . It is seen that the values of rates of production gotten from the prediction analyses of the well using the two methods of analysis differ. The rate in 2020 was predicted to be 158 stb/day using decline curve analysis and $\mathbf{4 1 1 . 9 8 4} \mathrm{stb} / \mathrm{day}$ using material balance.
\end{abstract}

Index Term - Decline Curve Analysis; Material Balance; Oil Production; Prediction.

\section{INTRODUCTION}

Inefficient oil rate prediction poses challenge to the oil industry, some of which are:

- Wrong forecast of production: Operators miscalculate due to inefficient prediction of the rate of oil production from the wells they operate.

- Bad economic analysis: Economic viability of any oil and gas project is determined only with correct data of the project. When the production data of a well is wrongly calculated, the revenue and investment of the well will also be wrongly calculated.

For this, production has to be properly forecasted. There are several methods of doing this which includes production decline curve analysis. Decline curve analysis is important in determining the value of oil and gas wells in oil and gas economics. Decline curves are the most common means of forecasting oil and gas production. Decline curves have many advantages: they use data which is easy to obtain, they are easy to plot, they yield results on a time basis, and they are easy to analyse. Decline curves are also one of the oldest methods of predicting oil reserves [1]. Material balance method is also used in predicting oil production. There are several other methods used in predicting production, but in

Published on April 17, 2018.

Anyadiegwu Charley Iyke is with the Department of Petroleum Engineering, Federal University of Technology, Owerri, Nigeria. (e-mail: drcicanyadiegwu@yahoo.com).

Ohia Nnaemeka Princewill is with the Department of Petroleum Engineering, Federal University of Technology, Owerri, Nigeria. (e-mail: princepetra@yahoo.com). this work, concentration would be made on prediction using decline curve and material balance analyses.

\section{Production PREDICTION}

The techniques for relating production to time is known as decline curve analysis. There are three types of decline curves, although only two of the three techniques are commonly used. Exponential and hyperbolic production declines occur in many reservoirs [2]. While the third type, harmonic decline, is now believed to be uncommon, the method is still used as a conservative projection technique.

The determination of the most probable future life of a well and the estimate of its future production can sometimes be done by volumetric calculations, but sufficient data are not always available to eliminate all guess work.

In that case, the possibility of extrapolating the trend of some variable characteristics of such a producing well may be considerable help. The simplest and most readily available variable characteristic of a producing well is its production rate, and the logical way to determine the future life of a well by extrapolation is to plot this variable production rate either against time or cumulative production, extending the curves obtained to the economic limit. The point of intersection of the extrapolated curve with the economic limit then indicates the possible future life of the future oil recovery. With the future rate known, it is possible to determine the future total production or reserves of the well. This represents the beginning of the art that is since become more of a science known as decline curve analysis.

The purpose of decline curve analysis is to determine future production and ultimate recovery of wells with some production history [3]. Since it depends on a curve-fit of past performance, the accuracy is expected to be greater for a well with several months or years of uninterrupted production history than for a well with only a limited amount of history. The definition of decline curve can be represented both mathematically and graphically with both, the future life of a well can be determined [4].

In order to analyse what influence certain reservoir characteristics may have on the type of decline curves, it was first assumed that we are dealing with the idealized case of a reservoir, where water drive is absent and where the pressure is proportional to the amount of remaining oil [5]. It was further assumed that the productivity index of the wells is constant throughout their life, so that, the production rates are always proportional to the reservoir pressure. In such a hypothetical case, the relationship between cumulative oil produced and pressure would have to be linear and also the relationship between production rate and cumulative production. In most actual reservoirs, however, 
the above mentioned idealized conditions do not occur. Pressures usually are not proportioned to the remaining oil, but seem to decline at a gradually slower rate as the amount of remaining oil diminishes [6]. At the same time the productivity index is generally not constant but show a tendency to decline as the reservoir is being depleted and the gas oil ratios increase. The combined result of these two tendencies is a rate-cumulative relationship, which instead of being a straight line on co-ordinate paper; show up as a gentle curve convex towards the origin.

Existing decline curve analysis are based on Arps equations [7], and there has been a great number of papers on this topic. Fetkovich et al., developed concepts for decline curve forecasting and provided a theoretical basis for the Arps equations [8]. Cheng et al., used stochastic approach to evaluate the uncertainty in reserve estimation based decline curve analysis [9]. A stochastic reserve estimation using decline curve analysis using Monte Carlo simulation to obtain reserve distribution was discussed in [10]

Arps decline curve analysis is an empirical method and requires no knowledge of reservoir parameters. The application of the method involves estimating a parametric model to the historical production data using least squares method. There are many different curve fitting methods available, however there is no one clear method to handle unusual observations. The available methods lead to unsatisfactory results due to the influence of the unusual observation. This paper proposes a modification of Arps decline curve analysis using results from robust regression analysis where the unusual observations receives less weight compared with the other observations. The exponential decline curve is fitted using robust cube polynomial regression to obtain a better representation of the fluctuation of the historical production. The similar approach was developed for harmonic decline curve analysis. Inspired from growth curve modelling, a logistic decline curve is proposed to estimate the global trend and applied to the historical data. The robust trend curve fitting results Arps equations and logistic model are used to extrapolated the future production decline and compared with the reservoir simulation results to evaluate the proposed approach [11].

According to [12], estimating oil reserves is one of the most important phases of the work of a petroleum engineer since the solutions to the problems he deals with usually depend on a comparison of the estimated cost in terms of dollars, with the anticipated result in terms of barrels of oil. His recommendations to management regarding the best course of action are therefore normally based on the most favourable balance between these two. Specific engineering problems which require such a knowledge of recoverable oil reserves and a projection of future rates are: [a.] the exploitation and development of an oil reservoir; [b.] the construction of gasoline plants, pipelines and refineries; [c.] the division of ownership in unitized projects; [d.] the price to be paid in case of a sale or purchase of an oil property, and the magnitude of the loan which it will support; [e.] the proper depreciation rate for the investment in oil properties; and [f.] evaluation of the results of an exploration program.

Reference [12] reviewed the methods in use for estimating primary oil reserves and conducting production prediction and discusses the principles on which these methods are based. Particular emphasis is placed on how these methods change with the type of information available during the life cycle of an oil property.

According to [13], the material balance is a very important part of the reservoir engineer's toolbox that is being relegated to the background in today's reservoir evaluation workflow. Their paper examined some issues that normally preclude its regular use especially as a pre-step before moving into full reservoir simulation and the use of a new method of analysing the material balance equation called the dynamic material balance method for solving some of these issues. The dynamic material balance method allows the simultaneous determination of the initial oil-inplace $(\mathrm{N})$ or initial gas-in-place $(\mathrm{G})$, ratio of initial gas to oil $(\mathrm{m})$, reservoir permeability $(\mathrm{K})$ or skin factor $(\mathrm{S})$ and average pressure history of a reservoir from the combination of solution to the material balance equation and pressure transient analysis theory. Cumulative production history and PVT data of the reservoir are used with limited or no pressure data. By introducing a time variable into the classical material balance equation (MBE) and combining the solutions of the resulting equations with the theory of pressure transient analysis, the cumulative production history of the reservoir and readily available PVT data of the reservoir fluids, they postulated that we can estimate not only the original reserves in place, but also determine the average reservoir pressure decline history as indicated by the net fluid withdrawal from the reservoir. The reservoir permeability and skin factor can then be estimated from the already determined average pressure decline history. Their method is expected to improve the use of material balance by expanding the list of problems that can be tackled using material balance especially to reservoirs in marginal fields and reservoirs in which limited pressure data is available.

\section{Methodology}

\section{A. Decline Curve Analysis}

A decline curve of a well is simply a plot of the well's production rate on the $y$-axis versus time on the $\mathrm{x}$-axis. The plot is usually done on a semi-log paper; i.e. the y-axis is logarithmic and the $\mathrm{x}$-axis is linear. When the data plots as a straight line, it is modelled with a constant percentage decline "exponential decline". When the data plots concave upward, it is modelled with a "hyperbolic decline". A special case of the hyperbolic decline is known as "harmonic decline".

The most common decline curve relationship is the constant percentage decline (exponential). With more and more low productivity wells coming on stream, there is currently a swing toward decline rates proportional to production rates (hyperbolic and harmonic). Although some wells exhibit these trends, hyperbolic or harmonic decline extrapolations should only be used for these specific cases. Over-exuberance in the use of hyperbolic or harmonic relationships can result in excessive reserves estimates. Fig. 1 is an example of a production graph with exponential and harmonic extrapolations. 


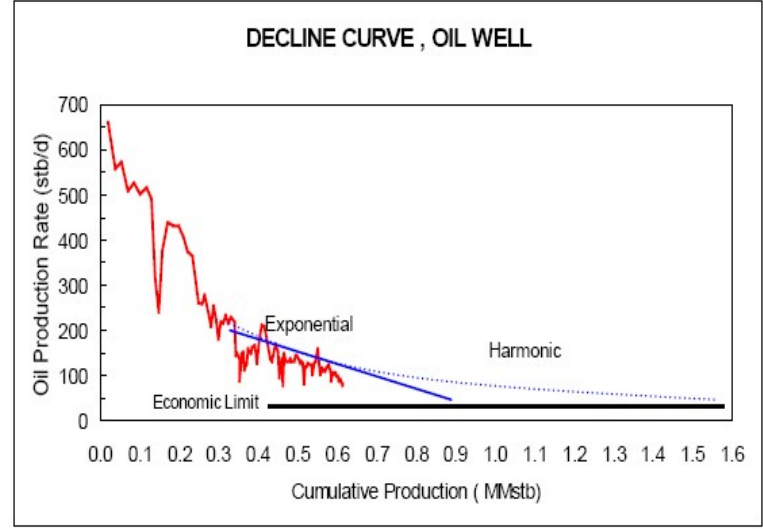

Fig. 1. Decline curve of an oil well

Decline curves are the most common means of forecasting production. They have many advantages: Data is easy to obtain, they are easy to plot, they yield results on a time basis, they are easy to analyse.

If the conditions affecting the rate of production of the well are not changed by outside influences, the curve will be fairly regular, and, if projected, will furnish useful knowledge as to the future production of the well.

According to [12], a production history may vary from a straight line to a concave upward curve. In any case the object of decline curve analysis is to model the production history with the equation of a line. The following table summarizes the five approaches for using the equation of a line to forecast production.

TABLE I: APPROACHES FOR PRODUCTION FORECAST

\begin{tabular}{llll}
\hline \hline $\begin{array}{l}\text { Log Rate-Time } \\
\text { Shape }\end{array}$ & Name & Model & Decline \\
\hline $\begin{array}{l}\text { Straight } \\
\text { Straight }\end{array}$ & Exponential & & $\begin{array}{l}\text { Stepwise } \\
\text { Continuous } \\
\text { straight }\end{array}$ \\
$\begin{array}{l}\text { Curved but } \\
\text { converging }\end{array}$ & Hyperbolic & Arps & $\begin{array}{l}\text { Continuous curve } \\
\text { Continuous curve } \\
\text { which nearly } \\
\text { Curved but limit }\end{array}$ \\
Harmonic & Arps & $\begin{array}{l}\text { Dual - Infinite } \\
\text { acting amended to } \\
\text { a limiting curve }\end{array}$ \\
\hline $\begin{array}{l}\text { Curved but not } \\
\text { converging }\end{array}$ & Amended & & \\
\hline \hline
\end{tabular}

\section{1) Exponential Decline}

As mentioned above, in the exponential decline, the well's production data plots as a straight line on a semi-log paper. The equation of the straight line on the semi-log paper is given in Table II.

Where:

$\mathrm{q}=$ well's production rate at time $\mathrm{t}, \mathrm{STB} /$ day

$\mathrm{q}_{\mathrm{i}}=$ well's production rate at time $0, \mathrm{STB} /$ day

$\mathrm{D}=$ nominal exponential decline rate, $1 /$ day

$\mathrm{t}=$ time, day

The following table summarizes the equations used in exponential decline.

TABLE II: EXPONENTIAL DECLINE EQUATIONS, B = 0 (PETROBJECTS, 2004)

\begin{tabular}{ll}
\hline \hline Description & Equation \\
\hline Rate & $q=q_{i} e^{-D t}$ \\
Cumulative Oil Production & $N_{p}=\left(q_{i}-q\right) / D$
\end{tabular}

$$
\begin{array}{ll}
\text { Nominal Decline Rate } & D=-\ln \left(1-D_{e}\right) \\
& D_{e}=\left(q_{i}-q\right) / q_{i} \\
\text { Effective Decline Rate } & D_{e}=1-e^{-D} \\
\text { Life } & t=\ln \left(q_{i} / q\right) / D
\end{array}
$$

\section{2) Hyperbolic Decline}

Alternatively, if the well's production data plotted on a semi-log paper concaves upward, then it is modelled with a hyperbolic decline. The equation of the hyperbolic decline is

Where:

$\mathrm{q}=$ well's production rate at time $\mathrm{t}, \mathrm{STB} /$ day

$\mathrm{q}_{\mathrm{i}}=$ well's production rate at time $0, \mathrm{STB} /$ day

$\mathrm{D}_{\mathrm{i}}=$ initial nominal exponential decline rate $(\mathrm{t}=0)$, $1 /$ day

\begin{tabular}{|c|c|c|}
\hline Description & Equation & \\
\hline Rate & $q=q_{i}\left(1+b D_{i} t\right)^{-1 / b}$ & (7) \\
\hline $\begin{array}{l}\text { Cumulative } \\
\text { Oil Production }\end{array}$ & $N_{p}=\left[q_{i}^{b}\left(q_{i}^{1-b}-q^{1-b}\right)\right] / D_{i}(1-b)$ & (8) \\
\hline $\begin{array}{l}\text { Nominal } \\
\text { Decline Rate }\end{array}$ & $D_{i}=\left[\left(1-D_{e i}\right)^{-b}-1\right] / b$ & (9) \\
\hline $\begin{array}{l}\text { Nominal } \\
\text { Decline Rate }\end{array}$ & $D_{e i}=\left(q_{i}-q\right) / q_{i}$ & (10) \\
\hline $\begin{array}{l}\text { Effective } \\
\text { Decline Rate }\end{array}$ & $D_{e}=1-e^{-D}$ & (11) \\
\hline Life & $t=\left[\ln \left(q_{i} / q\right)^{b}-1\right] / b D_{i}$ & (12) \\
\hline
\end{tabular}

$\mathrm{b}=$ hyperbolic exponent

$\mathrm{t}=$ time, day

The following table summarizes the equations used in hyperbolic decline:

TABLE III: Hyperbolic DeCline Equations, $\mathrm{B}>0$, $\mathrm{B} \neq 1$ (PetrobJeCtS,

\section{3) Harmonic Decline}

A special case of the hyperbolic decline is known as harmonic decline, where $\mathrm{b}$ is taken to be equal to 1 . The following table summarizes the equations used in harmonic decline:

TABLE IV: HARMonic DeCline EquATIONS, B = 1 (PetrobJects, 2004) [14]

\begin{tabular}{ll}
\hline \hline Description & Equation \\
Rate & $q=q_{i}\left(1+b D_{i} t\right)^{-1 / b}$ \\
Cumulative & $(13)$ \\
Oil Production & $N_{p}=\left(q_{i} / D_{i}\right) \ln \left(q_{i} / q\right)$ \\
$\begin{array}{l}\text { Nominal } \\
\text { Decline Rate }\end{array}$ & $D_{i}=\left[D_{e i} /\left(1-D_{e i}\right)\right]$ \\
Effective & $D_{e i}=\left(q_{i}-q\right) / q_{i}$ \\
Decline Rate & $t=\left[\left(q_{i} / q\right)-1\right] / D_{i}$ \\
Life & $t$
\end{tabular}

B. Material Balance Analysis using $M B A L$

For the prediction of the production of a well using material balance method with MBAL, the production history and data of the well are obtained. These data are used on MBAL. Efficient reservoir development requires a good understanding of reservoir and production systems. MBAL helps the engineer better define reservoir drive mechanisms and hydrocarbon volumes. This is a prerequisite for reliable simulation studies. MBAL is commonly used for modelling given in Table III. 
the dynamic reservoir effects prior to building a numerical simulator model.

MBAL contains the classical reservoir engineering tool and has redefined the use of Material Balance in modern reservoir engineering.

For existing reservoirs, MBAL provides extensive matching facilities. Realistic production profiles can be run for reservoirs with or without history matching.

MBAL is an intuitive program with a logical structure that enables the reservoir engineer to develop reliable reservoir models quickly.

\section{RESULTS}

\section{A. Case for Decline Curve Analysis}

Data were collected for a well. The production history for the well is presented in Tables V(a) and VI(f).

TABLE V(A): Production History of Well A

\begin{tabular}{llll}
\hline \hline Year & Time, year & $\begin{array}{l}\text { Oil Rate }(\mathrm{Q}), \\
\text { stb/day }\end{array}$ & $\begin{array}{l}\text { Cumulative } \\
\text { Production } \\
\left(\mathrm{N}_{\mathrm{p}}\right), \mathrm{stb}\end{array}$ \\
\hline 1990 & 1 & 2398 & \\
1991 & 2 & 1500 & 863280 \\
1992 & 3 & 1411 & 1403280 \\
1993 & 4 & 1320 & 1911240 \\
1994 & 5 & 1195 & 2386440 \\
1995 & 6 & 1083 & 2816640 \\
1996 & 7 & 904 & 3206520 \\
1997 & 8 & 900 & 3531960 \\
1998 & 9 & 837 & 3855960 \\
1999 & 10 & 812 & 4157280 \\
2000 & 11 & 789 & 4449600 \\
2001 & 12 & 774 & 4733640 \\
2002 & 13 & 700 & 5012280 \\
2003 & 14 & 593 & 5264280 \\
2004 & 15 & 529 & 5477760 \\
2005 & 16 & 506 & 5668200 \\
2006 & 17 & 487 & 5850360 \\
2007 & 18 & 440 & 6025680 \\
2008 & 19 & 418 & 6184080 \\
2009 & 20 & 415 & 6334560 \\
\hline \hline
\end{tabular}

The production history is to be used to predict rate of flow from the well up till 2020. Using the data in Table V(a) for Well A, the semi-log plot of $\mathrm{Q}$ against Time in years is shown in Fig. 2(a) below:

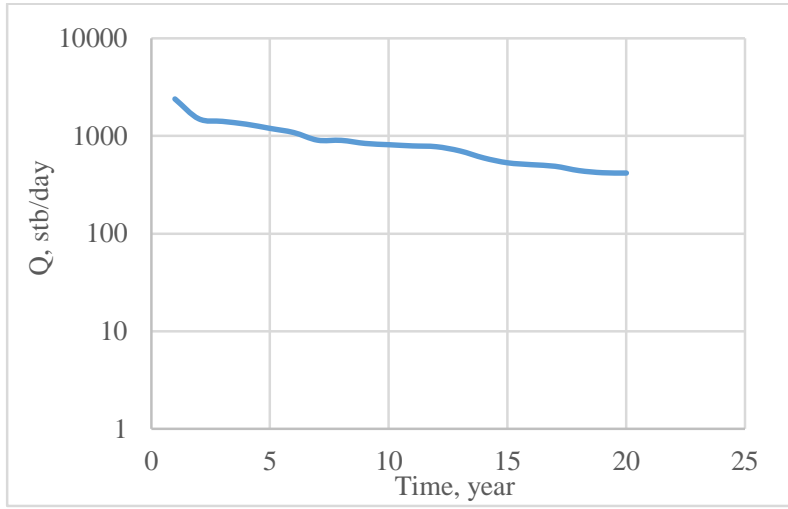

Fig. 2(a). Semi-log Plot of Q against Time (1990 - 2009)
From Fig. 2(a), it can be seen that the plot is approximately linear, therefore the exponential decline method can be used to predict the rate of production from the well at any particular time.

From Table II, the effective decline rate, $D_{e}$ for the 20 years can be evaluated as:

$$
\mathrm{D}_{\mathrm{e}}=(2398-415) /(2398)=0.827 / 20=0.04135 / \text { year }
$$

Then the nominal decline rate, $\mathrm{D}$ is:

$$
\mathrm{D}=-\ln (1-0.827)=1.754 / 20=0.0877 / \text { year }
$$

The rate of flow at any time can be predicted from (1) in Table II. This is used to estimate the rate of flow from the well from 2010 till 2020 as shown in Table V(b):

\begin{tabular}{|c|c|c|c|}
\hline Year & Time, year & $\begin{array}{l}\text { Oil Rate } \\
\text { (Q), stb/day }\end{array}$ & $\begin{array}{l}\text { Cumulative } \\
\text { Production } \\
\left(\mathrm{N}_{\mathrm{p}}\right), \text { stb }\end{array}$ \\
\hline 1990 & 1 & 2398 & \\
\hline 1991 & 2 & 1500 & 863280 \\
\hline 1992 & 3 & 1411 & 1403280 \\
\hline 1993 & 4 & 1320 & 1911240 \\
\hline 1994 & 5 & 1195 & 2386440 \\
\hline 1995 & 6 & 1083 & 2816640 \\
\hline 1996 & 7 & 904 & 3206520 \\
\hline 1997 & 8 & 900 & 3531960 \\
\hline 1998 & 9 & 837 & 3855960 \\
\hline 1999 & 10 & 812 & 4157280 \\
\hline 2000 & 11 & 789 & 4449600 \\
\hline 2001 & 12 & 774 & 4733640 \\
\hline 2002 & 13 & 700 & 5012280 \\
\hline 2003 & 14 & 593 & 5264280 \\
\hline 2004 & 15 & 529 & 5477760 \\
\hline 2005 & 16 & 506 & 5668200 \\
\hline 2006 & 17 & 487 & 5850360 \\
\hline 2007 & 18 & 440 & 6025680 \\
\hline 2008 & 19 & 418 & 6184080 \\
\hline 2009 & 20 & 415 & 6334560 \\
\hline 2010 & 21 & 380 & 8407511.24 \\
\hline 2011 & 22 & 348 & 8540523.83 \\
\hline 2012 & 23 & 319 & 8662368.1 \\
\hline 2013 & 24 & 292 & 8773981.79 \\
\hline 2014 & 25 & 268 & 8876223.92 \\
\hline 2015 & 26 & 245 & 8969881.35 \\
\hline 2016 & 27 & 225 & 9055674.89 \\
\hline 2017 & 28 & 206 & 9134264.83 \\
\hline 2018 & 29 & 188 & 9206256.03 \\
\hline 2019 & 30 & 173 & 9272202.52 \\
\hline 2020 & 31 & 158 & 9332611.86 \\
\hline
\end{tabular}

TABLE V(B): RATE of Flow ANd CUMULATIVE PRoduction PREDiction

The semi-log plot of Flow rate against time covering 1990 to 2020 is shown in Fig. 2(b): 


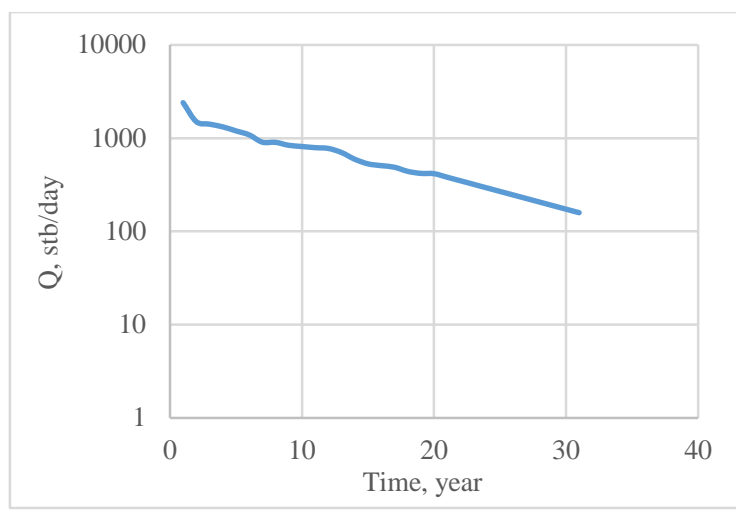

Fig. 2(b). Semi-log Plot of Q against Time (1990 - 2020)

The Cartesian plot of Flow rate against Year covering 1990 to 2020 is shown in Fig. 2(c).

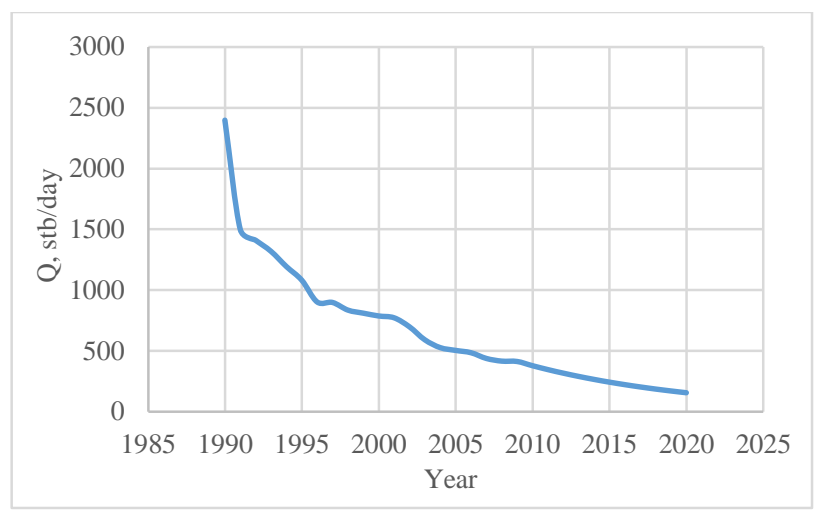

Fig. 2(c). Plot of Q against Time (1990 - 2020)

The Cartesian plots of Cumulative Production against Time covering 1990 to 2020 are shown in Fig. 2(d) and 2(e).

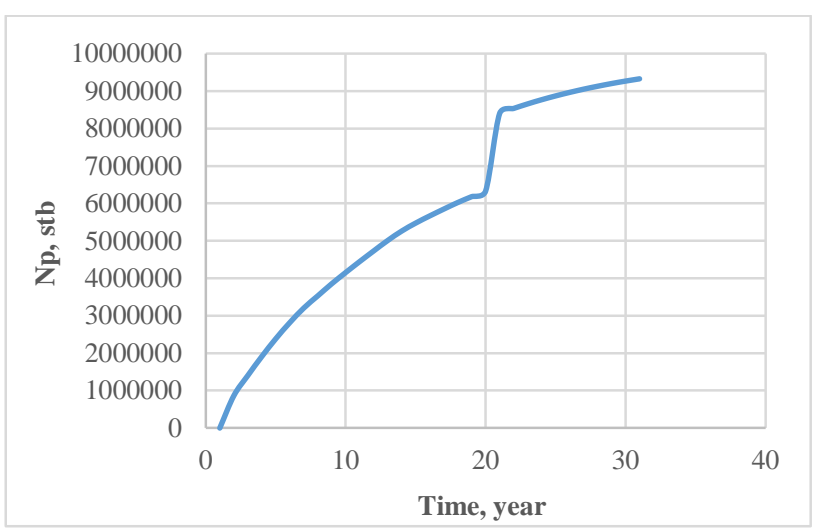

Fig 2(d). Plot of $\mathrm{N}_{\mathrm{p}}$ against Time $(1990-2020)$

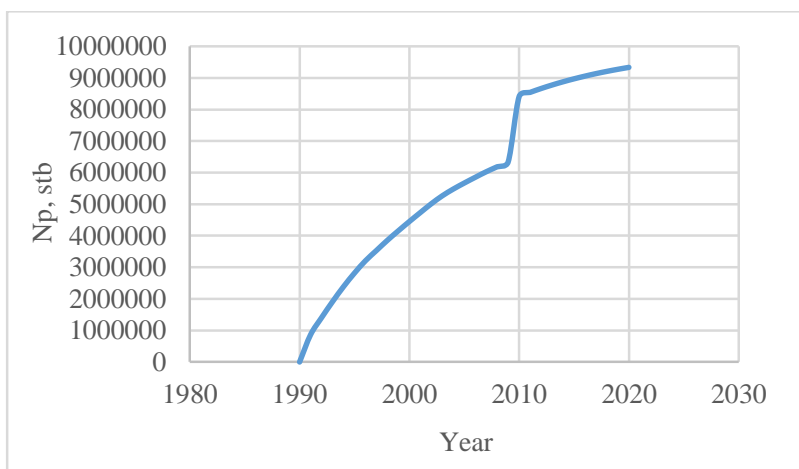

Fig 2(e). Plot of $\mathrm{N}_{\mathrm{p}}$ against Year $(1990-2020)$

\section{B. Production Prediction of Well A using Material Balance}

The reservoir and well data for prediction of production using material balance method with MBAL is given in Tables VI(a) to VI(f).

\begin{tabular}{ll}
\multicolumn{2}{c}{ TABLE VI(A): PVT DATA } \\
\hline \hline Parameter & Value \\
\hline GOR & $1720 \mathrm{scf} / \mathrm{stb}$ \\
Oil Gravity & $41.9 \mathrm{API}$ \\
Gas Gravity & 0.65 \\
Water Salinity & $10000 \mathrm{ppm}$ \\
Mole \% Sulphide & 0 \\
Mole \% Carbon dioxide & 0 \\
Mole \% Nitrogen & 0 \\
\hline \hline
\end{tabular}

\begin{tabular}{ll}
\multicolumn{2}{c}{ TABLE VI(B): TANK DATA } \\
\hline \hline Parameter & Value \\
\hline Tank type & Oil \\
Temperature & $190^{\circ} \mathrm{F}$ \\
Initial Pressure & $4458 \mathrm{psig}$ \\
Porosity & 0.24 \\
Connate Water Saturation & 0.09 \\
Water Compressibility & Use Correlation \\
Initial Gas Cap & 0 \\
OOIP & $42 \mathrm{mmstb}$ \\
Start of Production & $01 / 01 / 1990$ \\
\hline \hline
\end{tabular}

TABLE VI(C): WATER INFLUX (CATER TRACY MODEL)

\begin{tabular}{lll}
\hline \hline Parameter & Value & Unit \\
\hline Res Thickness & 208.235 & feet \\
Res Radius & 14607.1 & feet \\
Outer/Inner Rad ratio & 39.9005 & \\
Encroachment Angle & 320.519 & degrees \\
Aquifer Permeability & 24.3658 & md \\
\hline \hline
\end{tabular}

TABLE VI(D): PORE VOLUME VS DEPTH

\begin{tabular}{ll}
\hline \hline Pore vol & Depth \\
\hline-1 & 10032 \\
0 & 10192 \\
1 & 10310 \\
\hline \hline
\end{tabular}

TABLE VI(E): RELATIVE PERMEABILITY

\begin{tabular}{|c|c|c|c|}
\hline & $\begin{array}{l}\text { Res Sat. } \\
\text { (fraction) }\end{array}$ & End Point & Exponent \\
\hline $\mathrm{K}_{\mathrm{rw}}$ & 0.09 & 0.8 & 3.6 \\
\hline $\mathrm{K}_{\mathrm{ro}}$ & 0.1 & 0.81 & 3.6 \\
\hline $\mathrm{K}_{\mathrm{rg}}$ & 0.05 & 0.8 & 3.6 \\
\hline
\end{tabular}

TABLE VI(F): PRODUCTION HISTORY

\begin{tabular}{llll}
\hline \hline Year & Time, year & $\begin{array}{l}\text { Oil Rate } \\
(\mathrm{Q}), \text { stb/day }\end{array}$ & $\begin{array}{l}\text { Cumulative } \\
\text { Production } \\
\left(\mathrm{N}_{\mathrm{p}}\right), \mathrm{stb}\end{array}$ \\
\hline 1990 & 1 & 2398 & 863280 \\
1991 & 2 & 1500 & 1403280 \\
1992 & 3 & 1411 & 1911240 \\
1993 & 4 & 1320 & 2386440 \\
1994 & 5 & 1195 & 2816640 \\
1995 & 6 & 1083 & 3206520 \\
1996 & 7 & 904 &
\end{tabular}




\begin{tabular}{llll}
1997 & 8 & 900 & 3531960 \\
1998 & 9 & 837 & 3855960 \\
1999 & 10 & 812 & 4157280 \\
2000 & 11 & 789 & 4449600 \\
2001 & 12 & 774 & 4733640 \\
2002 & 13 & 700 & 5012280 \\
2003 & 14 & 593 & 5264280 \\
2004 & 15 & 529 & 5477760 \\
2005 & 16 & 506 & 5668200 \\
2006 & 17 & 487 & 5850360 \\
2007 & 18 & 440 & 6025680 \\
2008 & 19 & 418 & 6184080 \\
2009 & 20 & 415 & 6334560 \\
\hline \hline
\end{tabular}

The first MBAL interface is as shown in Fig. 3(a) where you can start your analysis. The second interface is gotten by clicking Options to fill the system options as shown in Fig. 3(b).

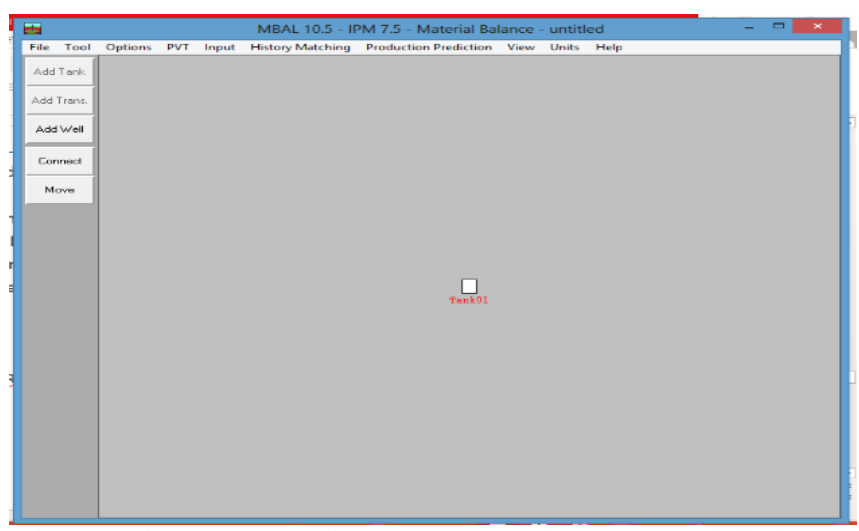

Fig. 3(a). First MBAL Interface (Source: Petroleum Experts Limited) [15]

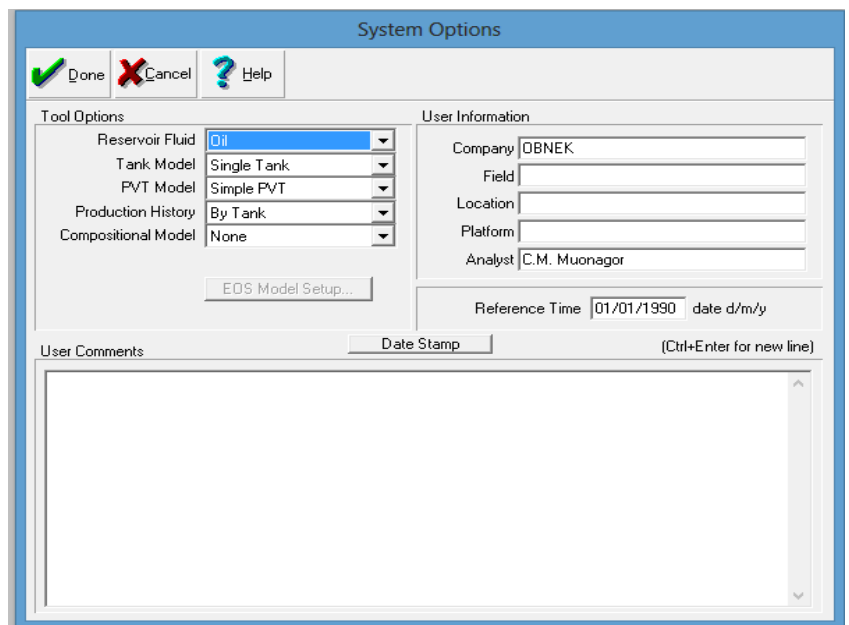

Fig. 3(b). MBAL Interface for System Options (Source: Petroleum Experts Limited) [15]

Then proceed to PVT on the material balance interface, click on PVT, click on Fluid Properties to fill the PVT data as shown in Fig. 3(c).

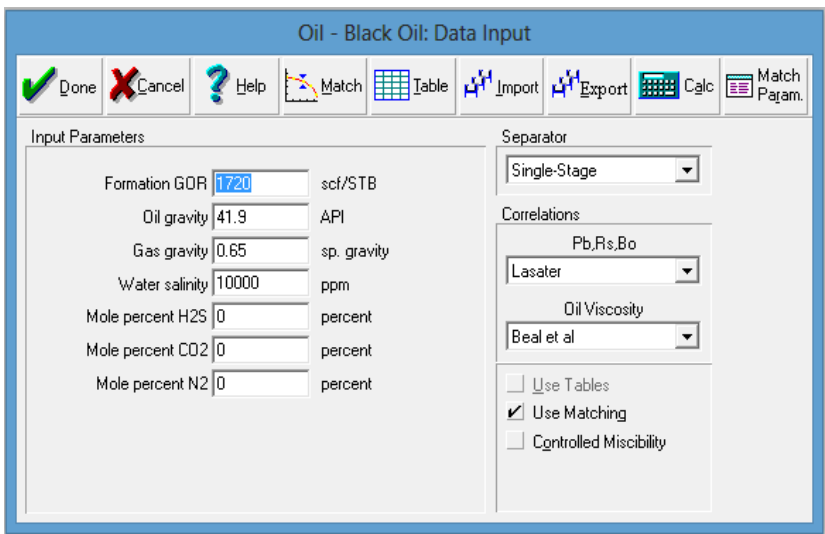

Fig. 3(c). MBAL Interface for Oil Data Input (Source: Petroleum Experts Limited) [15]

The next is to input the production history, tank parameters, pore volume vs depth, relative permeability etc. This is done by clicking Input and then clicking Tank data.

Then go to History Matching and click on Analytical Method and Energy Plot to generate the plot of tank pressure against calculated oil production for with water influx and without water influx and the plots of the effects of different energy drive mechanisms on the production of oil respectively. The Analytical Method and Energy Plots are as shown in Fig. 3(d) and 3(e) respectively.

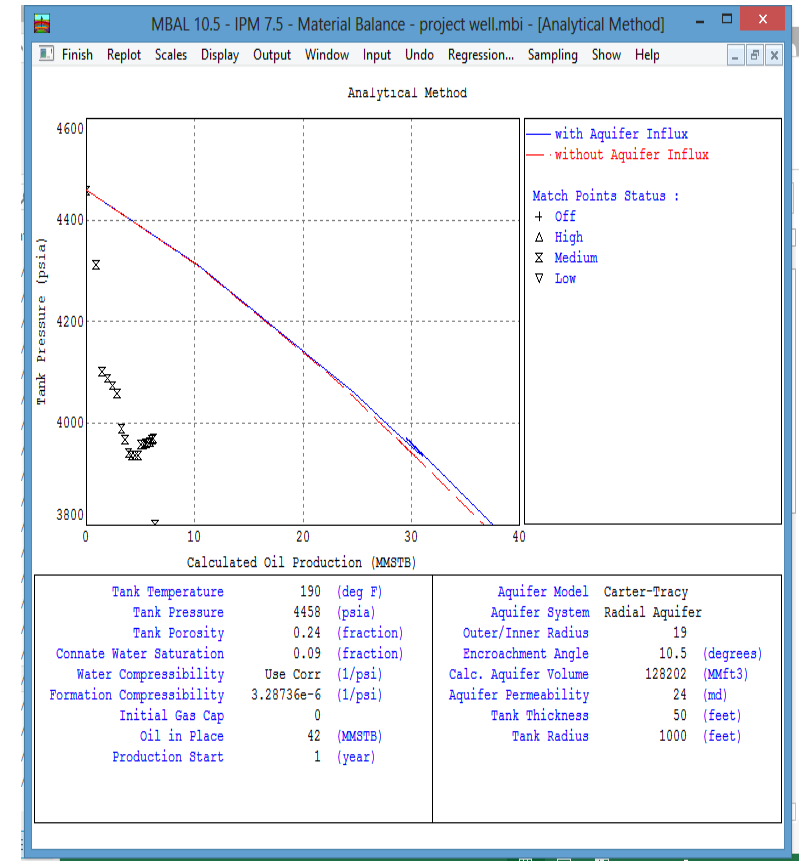

Fig. 3(d). MBAL Interface for Analytical Plot (Source: Petroleum Experts Limited) [15] 


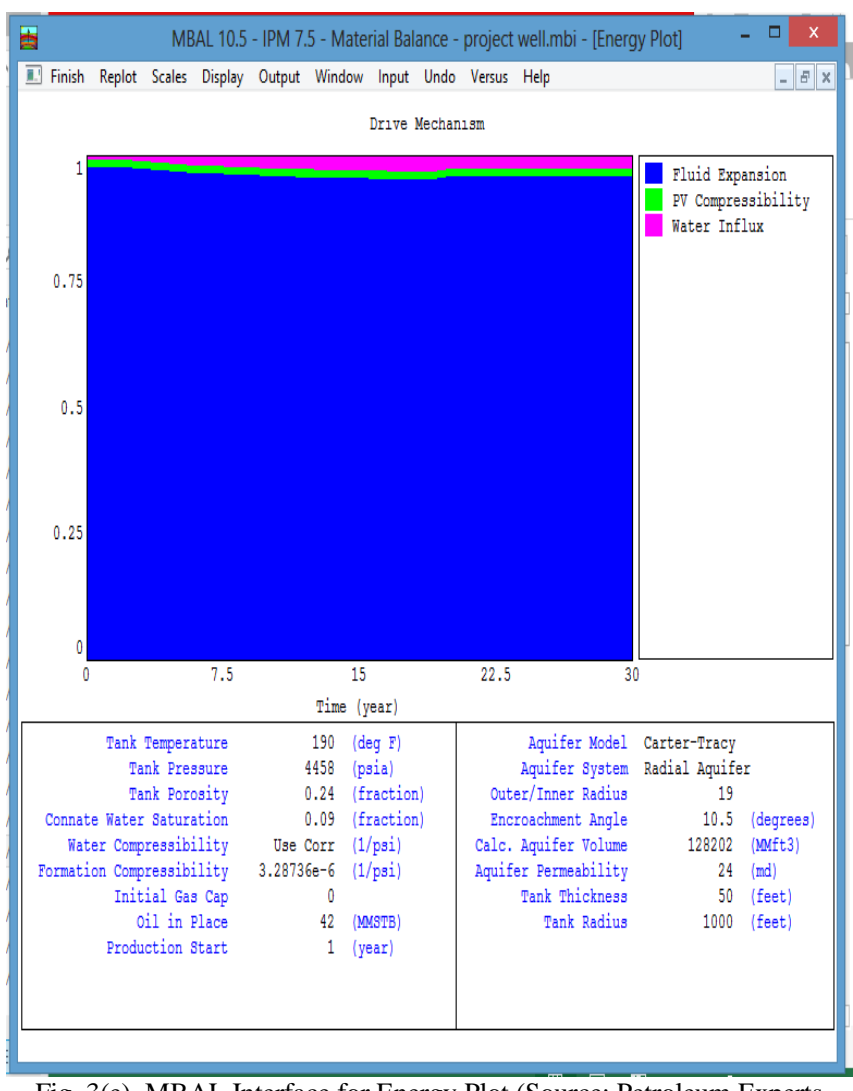

Fig. 3(e). MBAL Interface for Energy Plot (Source: Petroleum Experts Limited) [15]

On the same dropdown of History Matching, click Run Simulation, click Calc.

Move to Production Prediction, click on it, put the prediction setup, production and constraints, schedule and then click Run Prediction. The production prediction is performed and the results up till 2020 which is the well's $31^{\text {st }}$ year are extracted and as shown in Table VII.

TABLE VII: RESUlts of PRODUCTION PREDICTION USING MATERIAL

\begin{tabular}{lll}
\multicolumn{3}{c}{ BALANCE } \\
\hline \hline Time, year & Tank Pressure, psia & $\begin{array}{l}\text { Oil Rate }(\mathrm{Q}), \\
\text { stb/day }\end{array}$ \\
\hline 7.00 & 4149.85 & 890.99 \\
7.99 & 4118.49 & 890.99 \\
8.99 & 4087.14 & 887.047 \\
9.99 & 4057.93 & 824.954 \\
11.00 & 4029.43 & 777.645 \\
11.99 & 4001.73 & 777.645 \\
12.99 & 3974.44 & 762.861 \\
13.99 & 3949.72 & 689.926 \\
15.00 & 3928.74 & 521.387 \\
15.99 & 3910.05 & 521.387 \\
16.99 & 3892.08 & 498.718 \\
17.99 & 3874.69 & 479.991 \\
19.00 & 3858.89 & 411.984 \\
19.99 & 3843.84 & 411.984 \\
20.99 & 3828.67 & 411.984 \\
21.99 & 3813.40 & 411.984 \\
23.00 & 3797.97 & 411.984 \\
23.99 & 3782.46 & 411.984 \\
24.99 & 3766.83 & 411.984 \\
25.99 & 3751.06 & 411.984 \\
27.00 & 3735.11 & 411.984 \\
& & \\
& & \\
1 & &
\end{tabular}

\begin{tabular}{lll}
27.99 & 3719.04 & 411.984 \\
28.99 & 3702.81 & 411.984 \\
29.99 & 3686.39 & 411.984 \\
31 & 3669.72 & 411.984 \\
\hline \hline
\end{tabular}

\section{CONCLUSION}

Prediction analyses on a well were carried out in this paper. The result of the analyses has shown that the rate of oil production from a well can actually be predicted. Different rates were gotten for the different prediction analyses. The cumulative production of oil from well A was also predicted using decline curve analysis.

From the predictions made using the analyses, the following conclusions may be drawn:

1) The trend followed by the semi-log curve of the flow rate of oil against time determines the particular kind of decline curve prediction method to be used. Exponential decline is used when the decline is approximately linear or linear. Hyperbolic decline is used when the decline is a converging curve. Harmonic decline is used when the decline is a curve that has limit.

2) Different prediction methods give different values of rates of oil.

3) As much as the rate of flow of oil from the well can be predicted, the cumulative production of oil from the well can also be predicted.

4) The rate of oil predicted with material balance far differs from the rate of oil predicted with decline curve analysis.

5) The difference in the results got using decline curve and material balance analyses was due to the fact that the methods make use of variable estimation formulae and parameters. While decline curve analysis estimates decline of production taking into account only the production history, rate and the production decline rate, material balance analysis considers much more factors in estimating oil production from reservoirs. These other factors include oil formation factor, gas-oil ratio etc.

6) For accuracy in predicting production from a particular reservoir, first make a study of the particular production prediction method and trend that the neighbouring reservoirs or reservoirs of similar properties conform to, and apply same for the given reservoir.

\section{ACKNOWLEDGMENT}

We wish to thank the Almighty God for the strength $\mathrm{He}$ granted to us throughout the course of this research. We also wish to acknowledge some persons, who in one way or the other contributed to the success of this research work. Our thanks go to Engr. C.M. Muonagor and Engr. Prof. E.E. Anyanwu whose wealth of experience and knowledge contributed immensely to the progress of this work.

\section{REFERENCES}

[1] R. Thompson and J. Wright, Oil Property Evaluation, 2nd ed. Golden, Colorado: Thompson-Wright Associates, 1985, ch. 5.

[2] H. C. Slider, "A simplified method of hyperbolic decline curve analysis," Journal of Petroleum Technology, pp 235 - 236, vol. 20, issue 3, USA, 1968. 
[3] M. A. Mian, Project Economics and Decision Analysis: Deterministic Models-Volume 1, USA: PennWell Books, 2011, pp. 121.

[4] S. J. Pirson, "Mathematical method of decline curve extrapolation and reserve calculation," Oil Weekly, vol. 123, no. 2, pp. 45-49, Sept. 1946.

[5] K. Li and N. Roland, "A decline curve analysis model based on fluid flow mechanisms," presented at the SPE Western Regional/AAPG Pacific Section, Long Beach, California, May 19-24, 2003.

[6] J. Oloro, G. O. Odu, and O. Oyubu, "Application of decline curve analysis in predicting the life span of a well in Niger Delta reservoir," Continental Journal of Earth Sciences, vol. 6, no. 2, pp. 1-8, June. 2011.

[7] J. J. Arps, "Analysis of decline curves," Trans. AIME, pp 228 - 247, vol. 160, no. 1, USA, 1945.

[8] M. J. Fetkovitch, E. J. Fetkovitch, and M. D. Fetkovitch, "Useful concepts for decline curve forecasting, reserve estimation and analysis," SPE Reservoir Engineering, pp 13 - 22, vol. 11, no. 1, USA, 1996.

[9] Y. Cheng, Y. Wang, D. McVay, and M. Lee, "Practical application of a probabilistic approach to estimate reserves using production decline data," SPE Economics and Management, pp 19 - 31, vol. 2, no. 1, USA, 2010.

[10] V. A. Jochen and J. P. Spivey, "Probabilistic reserve estimation using decline curve analysis with the bootstrap method," presented at the SPE Annual Technical Conference and Exhibition, Denver, Colorado, October 6-9, 1996.

[11] D. Sutawanir D., N. R. Budi, and K. P. Asep, "Robust decline curve analysis," Journal of Indonesia. Mathematical. Society. (MIHMI), vol. 15 , no. 2 , pp. $105-111$, Oct. 2009.

[12] J. J. Arps, "Estimation of primary oil reserves," Trans. AIME, pp 182 - 191, vol. 207, no. 1, USA, 1956.

[13] K. P. Ojo and S. O. Osisanya, "Material balance revisited," presented at the Nigeria Annual International Conference and Exhibition, Abuja, Nigeria, July 31 - August 2, 2006.

[14] Decline Curves Estimation Methods, Petrobjects, Massachusetts, USA, 2004.

[15] MBAL, Reservoir Engineering Toolkit, Petroleum Experts Limited, Edinburgh, UK, 2010.

\section{NOMENCLATURE}

API $=$ American Petroleum Institute

$\mathrm{b}=$ Decline exponent

$\mathrm{D}=$ Decline rate

$\mathrm{D}=$ Nominal exponential decline

rate, $1 /$ day

$\mathrm{D}_{\mathrm{e}}=$ Effective exponential decline

rate, $1 /$ day

$\mathrm{D}_{\mathrm{i}}=$ Initial nominal exponential decline rate $(\mathrm{t}=0)$,

1/day

EIA = Energy Information Administration

GOR $=$ Gas-oil ratio

$\mathrm{K}_{\mathrm{rg}}=$ Gas relative permeability

$\mathrm{K}_{\mathrm{ro}}=$ Oil relative permeability

$\mathrm{K}_{\mathrm{rw}}=$ Water relative permeability

$\mathrm{md}=$ Millidarcy

MMstb $=$ Million stock tank barrel

$\mathrm{Np}=$ Cumulative oil production

OOIP $=$ Oil originally in place

$\mathrm{ppm}=$ Parts per million
PVT $=$ Pressure-Volume-Temperature $\mathrm{q}=$ Well's production rate at time

t, STB/day

$\mathrm{Q}=$ Oil rate, stb/day

$\mathrm{q}_{\mathrm{i}}=$ Well's production rate at time

$0, \mathrm{STB} /$ day

$\mathrm{Q}_{\mathrm{i}}=$ Oil rate at initial time

$\mathrm{Q}_{\mathrm{t}}=$ Oil rate at time,

$\mathrm{Q}_{11}=$ Oil rate at the $11^{\text {th }}$ year

$\mathrm{Q}_{20}=$ Oil rate at the $20^{\text {th }}$ year

Scf $=$ Standard cubic foot

$\mathrm{Stb} / \mathrm{d}=$ Stock tank barrel per day

$\mathrm{t}=$ Time, day

${ }^{0} \mathrm{~F}=$ Degree Fahrenheit

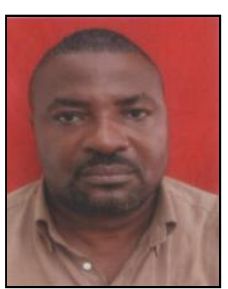

Anyadiegwu Charley Iyke is a senior lecturer with the Department of Petroleum Engineering, Federa University of Technology, Owerri, Imo State, Nigeria. He was born on November 7, 1970 at Nnewi, Anambra State, Nigeria. He earned a Ph.D. in Petroleum Engineering with Federal University of Technology, Owerri, Imo State, Nigeria in 2012. His major field of study is Petroleum Engineering (Oil and Gas).

He has been a lecturer in Petroleum and Gas Engineering since 1999 with Department of Petroleum Engineering, Federal University of Technology, Owerri, Imo State, Nigeria. He also works as an oil and gas engineering consultant for Sasog Oil and Gas Consult and Sigma Oil and Gas Consult, Port Harcourt, Nigeria. He worked previously as a postgraduate researcher with Shell Petroleum Development Company of Nigeria, Limited, Port Harcourt, Nigeria. He has authored and co-authored over 45 journal publications and has one book to his credit. The title of the book is Technical and Economic Evaluation of Gas Storage Reservoirs, Lambert Academic Publishing, Germany, 2012. Some of his publications include: Development and Application of CLOGEN-Polymer Slug as Enhanced Oil Recovery Agent in the Niger Delta Marginal Oil Fields; American Journal of Engineering Research, Volume 2, Issue 12, pp 16 - 38, U.S.A, 2013; Evaluating the Investment and Expected Revenue in an Oil Depleted Underground Gas Storage Reservoir with Water Influx: Petroleum and Coal, 56(4) 383 - 394, 2014, Slovakia Republic, 2014 Comparative Analysis of Using Natural Gas for Liquefied Natural Gas Production and Converting Natural Gas to Diesel Through Gas-To-Liquid Technology in Nigeria. International Journal of Research in Engineering and Science, Vol 2 Issue 9, September, 2014, pp. 09 - 26, India, 2014.

Engr. Dr. Anyadiegwu is member of some professional bodies which include: Council for Registered Engineers of Nigeria (COREN); Society of Petroleum Engineers, International (SPE).

Nnaemeka Ohia was born in Edo State Nigeria and commenced his primary school education in Northern Nigeria.

He has a PhD in Petroleum Engineering from the Federal University of Technology Owerri, Nigeria in the year 2012. His current research areas of interests include; well engineering, well intervention and completion, vertical performance optimization, wellbore fluids, oil pollution and control, etc.

Dr. Ohia is a member of the Nigerian Society of Engineer and the Council for the regulation of Engineering in Nigeria. HE also a member of the Society of Petroleum Engineers - International. 